\title{
Estimation of a Mechanization Index in Apple Orchard in Iran
}

\author{
Raheleh Fadavi (Correponding author), Alireza Keyhani \& Seyed Saeid Mohtasebi \\ Department of Agricultural Machinery Engineering, Faculty of Agricultural Engineering and Technology \\ University of Tehran, P. O. Box 4111, Karaj, Iran \\ Tel: 98-261-280-1011Ｅ-mail: fadavi.raheleh@gmail.com
}

\begin{abstract}
This study was conducted in production year 2008-9 in West Azerbaijan province (Uromia Township). mechanization index was estimated for apple (Red and Golden delicious varieties). In this study, data were collected by using random sampling method for 80 face to face questioners. Mechanization was considered in three levels including level 1 for spraying only, level 2 for spraying and plotting and level 3 for spraying and fertilizing operations. Results showed that by increasing Mechanization Index, energy and inputs' consumption will not decrease necessarily, suggesting that management of inputs consumption is more important.
\end{abstract}

Keywords: Tree apple, Mechanization index, Energy, Economic

\section{Introduction}

The common definition of mechanization involves all issues related to machines and their management in crop production in agriculture (Almasi et al., 2008). Mechanization is benefiting from technology, which is site-specific and dynamic (Singh, 2006). In order to adopt mechanization at a proper level, corresponding indices are necessary to be assessed. In this study, mechanization does not involve only mechanizing agricultural operations, rather effective factors in energy consumption and economic management are also considered in mechanization. In developed countries, the main object of mechanization is decreasing expenses and decreasing labour drudgery, but in developing countries, the main purpose of mechanization is increasing production.

Apple is one of the superior crops due to its nutrients and exporting value. In 2005, apple orchards' area was summed up to 201000 ha with total production of $2.66 \mathrm{Mt}$ in Iran (Anon., 2006a). West Azarbaijan province is the leading apple (Delicious \& Golden varieties with long legged, 277 trees per hectare) producer in Iran, with approximately $27.1 \%$ share of total apple orchard area and $29.8 \%$ share of total apple production in Iran (Anon., 2006a). Also, about half of this province's apple production and apple orchard area is allocated to Oromieh Township (Anon., 2005). Based on data from the Food and Agriculture Organization (FAO) of the United Nations in 2006, Iran is ranked third largest apple production in the world after China and USA (Anon., 2006b) (Table1).

$<$ Table 1>

Apple is a crop requiring high-energy inputs for successful commercial production of a high-quality fruit. Considerable research studies have been conducted on mechanization in agriculture, however, relatively little attention has been paid to apple production.

Van Den Berg et al. (2007), reported that increasing of farm size requires mechanization utilization, on the other hand these two factors are considerable in farmer 's production and income. Nkakini et al. (2006), investigated that mechanized methods require less energy than manual methods. Chen et al. (2008), revealed that mechanization utilization has caused to productivity growth in agriculture in Chin at 1990- 2003 years.

The aims of this study were to estimation of a mechanization index in apple orchards in Oromieh Township in Iran.

\section{Materials and methods}

The West Azarbaijan province is located in the northwestern of Iran, with $37590 \mathrm{~km}^{2}$ area (except Oromieh lake), within $44^{\circ} 3^{\prime}$ to $47^{\circ} 24^{\prime}$ eastern longitude, and $36^{\circ} 5^{\prime}$ to $39^{\circ} 46^{\prime}$ northern latitude. Neighboring with three foreign countries, it is considered an important province with regard to export.

Data were collected from 80 apple orchard in the Oromieh Township of West Azarbijan province by using a face to face questionnaire in 2008. Information was sought on inputs used for production of apple as well as economic characteristics of the orchards. Sample orchards were randomly selected from the villages in the study 
area by using a stratified random sampling technique. The sample size was calculated using the Cochran method as in Eq.1:

$$
\mathrm{n}=\mathrm{Nt}^{2} \mathrm{~S}^{2} /\left(\mathrm{Nd}^{2}+\mathrm{t}^{2} \mathrm{~S}^{2}\right)
$$

where:

$d$ - the precision where $(\mathrm{x}-\mathrm{X})$ or mid-confidence interval

$n$ - the required sample size

$N$ - the number of holdings in target population

$S^{2}$ - the variance of surveyed factor of population (energy and economic productivity)

$t$ - the reliability coefficient (1.96 which represents the $95 \%$ confidence interval)

The permissible error in the sample size was defined to be $5 \%$ for $95 \%$ confidence. The sample size was calculated as 77 orchards and increased to 80 to improve accuracy. Farmers' responses were obtained through face to face interviews, in production year in 2008. Before collecting data, the survey form was pre-tested by a group of randomly selected farmers and these pre-tested surveys were not included in the final data set.

A mechanization index based on the matrix of use of animate and mechanical energy inputs could be given by incorporating energy and cost factors in to Eqs (2) and (3), respectively (Singh, 2006):

$$
\begin{aligned}
& \mathrm{I}_{\mathrm{m}}=\mathrm{E}_{\mathrm{EM}} /\left(\mathrm{E}_{\mathrm{EM}}+\mathrm{E}_{\mathrm{EA}}+\mathrm{E}_{\mathrm{EH}}\right) \\
& \mathrm{I}_{\mathrm{m}}=\mathrm{C}_{\mathrm{EM}} /\left(\mathrm{C}_{\mathrm{EM}}+\mathrm{C}_{\mathrm{EA}}+\mathrm{C}_{\mathrm{EH}}\right)
\end{aligned}
$$

Where: $I_{m}$ is the mechanization index of the apple crop in the Oromieh Township; $E_{E M}$ and $C_{E M}$ are the energy and cost of use of machinery; $\mathrm{E}_{\mathrm{EA}}$ and $\mathrm{C}_{\mathrm{EA}}$ are the energy and cost of use of animal labour; $\mathrm{E}_{\mathrm{EH}}$ and $\mathrm{C}_{\mathrm{EH}}$ are the energy and cost of use of human labour (in this research, no animal energy is used).

Based on the energy equivalents of the inputs and outputs (table 2), the metabolisable energy was calculated.

$<$ Table 2>

In order to calculate inputs energy needed for irrigation (required energy for pumping water), Eq. (4) was used (Kitani, 1999):

$$
D E=\frac{\gamma g H Q}{\varepsilon_{p} \varepsilon_{q}}
$$

where:

$D E$ - direct energy (J/ha)

$g$ - acceleration due to gravity $\left(\mathrm{m} / \mathrm{s}^{2}\right)$

$H$ - total dynamic head (m)

$Q$ - volume of required water for one cultivating season $\left(\mathrm{m}^{3} / \mathrm{ha}\right)$

$\gamma$ - density of water $\left(\mathrm{kg} / \mathrm{m}^{3}\right)$

$\varepsilon_{p}$ - pump efficiency (70-90\%)

$\varepsilon_{q}$ - total power conversion efficiency (18-20\%) (Ercolia et al., 1999)

In this study, the required water was estimated $7000 \mathrm{~m}^{3}$ for one cultivating season. The inputs of the system include costs (or energy) of human labour, chemical fertilizers, chemicals biocides, packaging, transportation, refrigerating, fixed costs and agricultural machinery. All considered prices of inputs were averaged market prices in production year of 2008-2009.

\section{Results and discussion}

\subsection{Mechanization analysis of apple production}

Most agricultural operations are conducted using labour energy. In other words, the surveyed orchards are categorized as conventional. Therefore, the share of machine energy and its corresponding expenses were calculated to be insignificant at $1 \%$ probability level. The average mechanization index was calculated as 0.052 and 0.48 for expenses and energies, respectively.

According to results, orchardist do not utilize machines in order to prevent soil compaction and preserve soil structure. Even if fertilizing, plotting and other operations had been conducted by machines, mechanization 
index could not vary significantly due to the fact that the share of labour cost and energy of harvesting operation summed up to more than all other operations.

Tractors are utilized in fertilizing, plotting and spraying operations. Agricultural experts of the region believe that the correct method of fertilizing to make nutrients available to the root is fertilizer-pitting (burying fertilizer in depth of 30-40 cm of soil). In some of the orchards, fertilizing operation was implemented either by rotary tiller or manual on the surface of soil. In this case, fertilizer is not accessible to the root because of deep root of apple trees along with soil compaction due to the function and heavy weight of the rotary tiller. In the surveyed region, pitting operation was not mechanized; on the contrary, this was operated with labours leading to more expenses and time wasting.

Mechanization was considered in three levels that is level 1 for spraying only, level 2 for spraying and plotting and level 3 for spraying and fertilizing operations. Irrigating was carried out as semi- mechanized with deep wells or by river or dam in levels 2 and 3 while it was conventional in level 1 .

Fig.1. shows that increasing mechanization index causes to increase in machine expense while this fact could not lead to decrease in labour expense. Hasanzadeh \& Rahbar (2005), reported that the most energy consuming input for apple production in West Azarbaijan province was that for irrigation, nitrogen chemical fertilizing and chemical biocides, respectively. Strapatsa et al. (2006), calculated that the most energy inputs for orchard apple production in Greece were fuel $(33 \%)$, machinery $(25 \%)$ and fertilizers $(15 \%)$, mainly $\mathrm{N}$ (where orchards were irrigated 1-2 times a year), respectively, in all studies sited, postharvest operation were not included.

$<$ Figure 1 $>$

The cost of irrigation is increased in level 1 due to applying conventional method. Costs of packaging, transportation and refrigerating are increased by going from mechanization level 1 to 3 . This means that production is increased by increasing mechanization level (the method of packaging, transportation and refrigerating operation was similar in all apple orchards). Categorization of mechanization levels (based on mechanization index) is shown in table 3 and 4.

$<$ Table 3>

$<$ Table 4>

Fig. 2. shows that the energy of nitrogen fertilizer level 2 is less than that of other levels due to better inputs management.

$<$ Fig 2>

\section{Conclusions}

Data used in this study were collected from 80 farmers located in the Oromieh Township of West Azerbaijan province in Iran. In this study, energy management is important, Therefore, policies should emphasize on development of new technologies (application of new technologies such as packaging and irrigation are encouraged) and provide with alternative energy resources aiming efficient use of energy (use of Goldoni tractors instead of other common tractors can be saved in fuel consumption and also prevent of soil compaction). The results derived from this study can be used by policy makers and other relevant agencies for recommendations to farmers in order to use energy more efficiently.

The mean of mechanization index was calculated 0.052 and 0.48 for expends and energies respectively in apple orchards due to being conventional orchards, Mechanization was considered in three levels including level 1 for spraying only, level 2 for spraying and plotting and level 3 for spraying and fertilizing operations. Results showed that by increasing Mechanization Index, energy and inputs consumption will not decrease necessarily rather management of inputs consumption is more important.

\section{List of selected symbols}

$\mathrm{C}_{\mathrm{EA}}-$ cost of use of animal labour

$\mathrm{C}_{\mathrm{EH}}-$ cost of use of human labour

$\mathrm{C}_{\mathrm{EM}}-$ cost of use of machinery

$d$ - precision where $(x-X)$

$\mathrm{E}_{\mathrm{EM}}$ - energy of use of machinery

$\mathrm{E}_{\mathrm{EA}}$ - energy of use of animal labour

$\mathrm{E}_{\mathrm{EH}}-$ energy of use of human labour 
$g$ - gravitational acceleration $\left(\mathrm{m} / \mathrm{s}^{2}\right)$

$H$ - total dynamic head (m)

$\mathrm{I}_{\mathrm{m}} \quad-$ mechanization index

$n$ - required sample size

$N$ - number of holdings in target population

$Q-$ volume of required water for one cultivating season $\left(\mathrm{m}^{3} / \mathrm{ha}\right)$

$S^{2}$ - variance of surveyed factor of population

$t$ - reliability coefficient (1.96 in the case of $95 \%$ reliability)

$\varepsilon_{p} \quad$ - pump efficiency

$\varepsilon_{q} \quad-$ total energy and power conversion efficiency

$\gamma$ - density of water $\left(\mathrm{kg} / \mathrm{m}^{3}\right)$

\section{References}

Almasi, M., Kiyani, SH., \& Lavaimi, N. (2005). Principles of Agricultural Mechanization. Iran: Hazrate Maesomeh Pub.

Anonymous. (2005). Agricultural Census of 2003 in Azarbaijane Gharbi Province: The Statistics Center of Iran. Iran: The Office of Publication and Information Pub.

Anonymous. (2006a). Agriculture Statistics- Production of agriculture and gardening: production year 2004-5. (Vol.I). Iran: MAJ Pub.

Anonymous. (2006b). Food and Agriculture Organization (FAO). [Online] Available: http://www.fao.org. (Jun11, 2009)

Anonymous. (2007b). Institute of Standards and Industrial Research of Iran: The International lists of Iran. [Online] Available at: http://www. isiri.org. (May30, 2009)

Chen, P. C., Yu, M. M., Chang, C. C., \& Hsu, S. H. (2008). Total factor productivity growth in China 's agricultural sector. Journal of China Economic Review, 19, 580-593.

Ercolia, L., Mariottib, M., Masonib, A., \& Bonaria, E. (1999). Effect of irrigation and nitrogen fertilization on biomass yield and efficiency of energy use in crop production of Miscanthus. Journal of Field Crops Research, 63, 68-81.

Hasanzadeh, A., \& Rahbar, S. (2005, November 10-12). Study of energy flow in apple orchards Azarbaijane Gharbi Province. The $4^{\text {th }}$ Iranian Congress on Horticultural Science. Ferdosi Mashad University. Mashad, Iran.

Helsel, Z.R. (1992). In: Fluck RC, editor. Energy and alternatives for fertilizer and pesticide use in "Energy in world agriculture'. (Vol. 6). Amsterdam: Elsevier Science Pub, 177-210.

Kitani, O. (1999). CIGR: Handbook of Agricultural Engineering: Energy and Biomass Engineering. (Vol. V). ASAE publication, St Joseph, MI.

Nkakini, S. O., Ayotamuno, M. J., Ogaji, S. O. T., \& Probert, S. D. (2006). Farm mechanization leading to more effective energy-utilization for cassava and yam cultivation in Rivers State, Nigeria. Journal of Applied Energy, $83,1317-1325$.

Singh, G. (2006). Estimation of Mechanisation Index and its Impact on production and economic factors-a case study in India. Journal of Biosystems Engineering, 93, 99-106.

Singh, S., \& Mittal, J. P. (1992). Energy in Production Agriculture. New Delhi: Mittal Pub.

Strapatsa, A. V., Nanos, G. D., \& Tsatsarelis, C. A. (2006). Energy flow for integrated apple production in Greece. Journal of Ecosystem \& Environment, 116, 176-180.

Van Den Berg, M. M., Hengsdijk, H., Wolf, J., Van Ittersum, M.K., Guanghuo, W., \& Roetter, R. P. (2007). The impact of increasing farm size and mechanization on rural income and rice production in Zhejiange province, China. Journal of Agricultural Systems, 94, 841-850. 
Table 1. The production of apples in some important apple producing countries in 2006 (Anonymous., 2006b)

\begin{tabular}{lc}
\hline Countries & Production quantity (ton) \\
\hline China & 26065500 \\
USA & 4568630 \\
Iran & 2661901 \\
Poland & 2304892 \\
Italy & 2112720 \\
Turkey & 2002033 \\
India & 1739000 \\
\hline
\end{tabular}

Table 2. Energy equivalents of inputs and output in agricultural production

\begin{tabular}{lcc}
\hline Inputs (unit) & Energy equivalent (MJ/unit) & Reference \\
\hline 1. Chemical fertilizers (kg) & & \\
(a) Nitrogen & $78.1 \mathrm{MJ} / \mathrm{kg}$ & Kitani, 1999 \\
(b) Phosphate (P2O5) & $17.4 \mathrm{MJ} / \mathrm{kg}$ & Kitani, 1999 \\
(c) Potassium (K2O) & $13.7 \mathrm{MJ} / \mathrm{kg}$ & Kitani, 1999 \\
(d) Superior Chemical & $120 \mathrm{MJ} / \mathrm{kg}$ & Singh \& Mittal, 1992 \\
2. Farmyard manure (kg) & $0.0303 \mathrm{MJ} / \mathrm{kg}$ & Singh \& Mittal, 1992 \\
3. Chemical biocides (L) & & \\
(a) Insecticides & $199 \mathrm{MJ} / \mathrm{L}$ & Helsel, 1992 \\
$\quad$ (b) Benomyl & $397 \mathrm{MJ} / \mathrm{L}$ & Kitani, 1999 \\
$\quad$ (c) Captan & $115 \mathrm{MJ} / \mathrm{L}$ & Kitani, 1999 \\
$\quad$ (d) Other fungicides & $92 \mathrm{MJ} / \mathrm{L}$ & Helsel, 1992 \\
4. Diesel fuel (L) & $47.8 \mathrm{MJ} / \mathrm{L}$ & Kitani, 1999 \\
5. Electricity (kWh) & $12 \mathrm{MJ} / \mathrm{kWh}$ & Kitani, 1999 \\
6. Wood (packaging) (kg dry mass) & $18 \mathrm{MJ} / \mathrm{kg}$ & Singh \& Mittal, 1992 \\
7. Transportation (t.km) & $2.6 \mathrm{MJ} / \mathrm{t} . \mathrm{km}$ & Kitani, 1999 \\
8. Tractor (kg) & $138 \mathrm{MJ} / \mathrm{kg}$ & Kitani, 1999 \\
9. Fertilizer (sprayer) (kg) & $129 \mathrm{MJ} / \mathrm{kg}$ & Kitani, 1999 \\
10. Disk harrow (kg) & $149 \mathrm{MJ} / \mathrm{kg}$ & Kitani, 1999 \\
11. Human labour (h) & $0.27 \mathrm{MJ} / \mathrm{h}$ & Kitani, 1999 \\
13. Refrigerating (t.day) & $1.151 \mathrm{MJ} / \mathrm{t} . \mathrm{day}$ & Anonymous., 2007b \\
\hline
\end{tabular}

Table 3. Classification of mechanization levels based on mechanization index of cost

\begin{tabular}{lccc}
\hline Levels of mechanization & Frequency & quantity & specification \\
\hline Level 1 & 15 & $0.01-0.032$ & Spraying \\
Level 2 & 33 & $0.032-0.05$ & Spraying-plotting \\
Level 3 & 32 & $0.05-0.14$ & Spraying-fertilizing \\
\hline
\end{tabular}


Table 4. Classification of mechanization levels based on mechanization index of input energy

\begin{tabular}{lccc}
\hline Levels of mechanization & Frequency & quantity & specification \\
\hline Level 1 & 12 & $0.02-0.25$ & Spraying \\
Level 2 & 26 & $0.25-0.49$ & Spraying-plotting \\
Level 3 & 42 & $0.49-0.8$ & Spraying-fertilizing \\
\hline
\end{tabular}

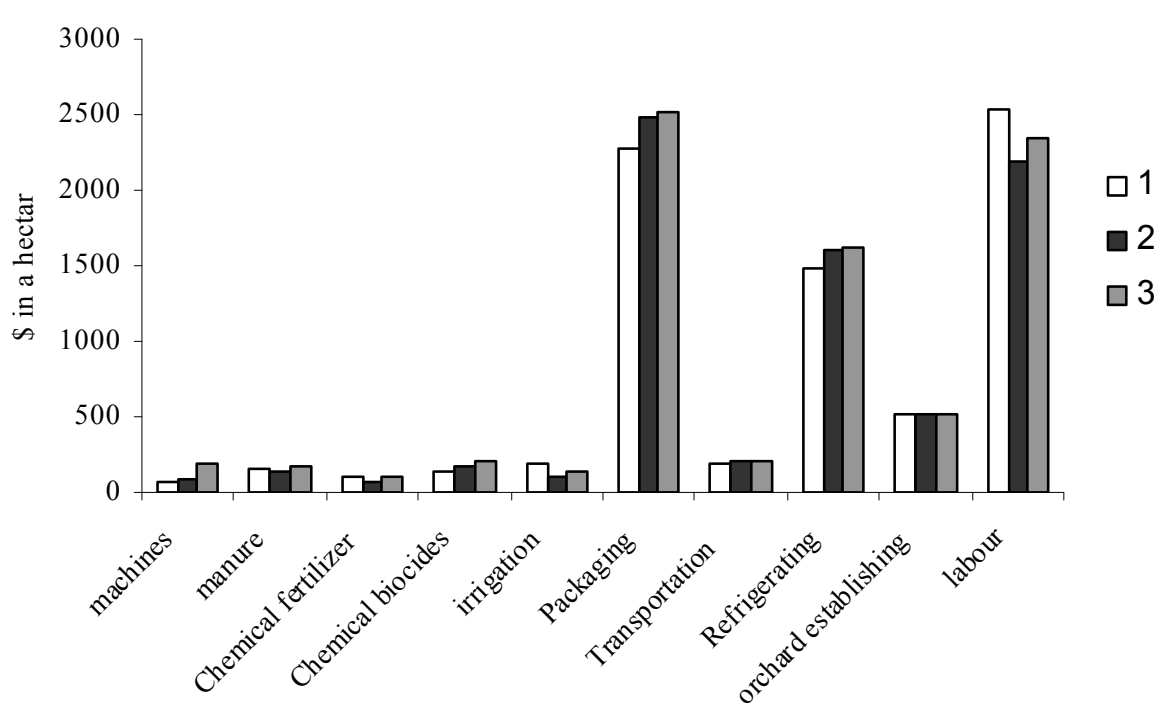

Figure 1. The percentage of the expenses in the mechanization levels

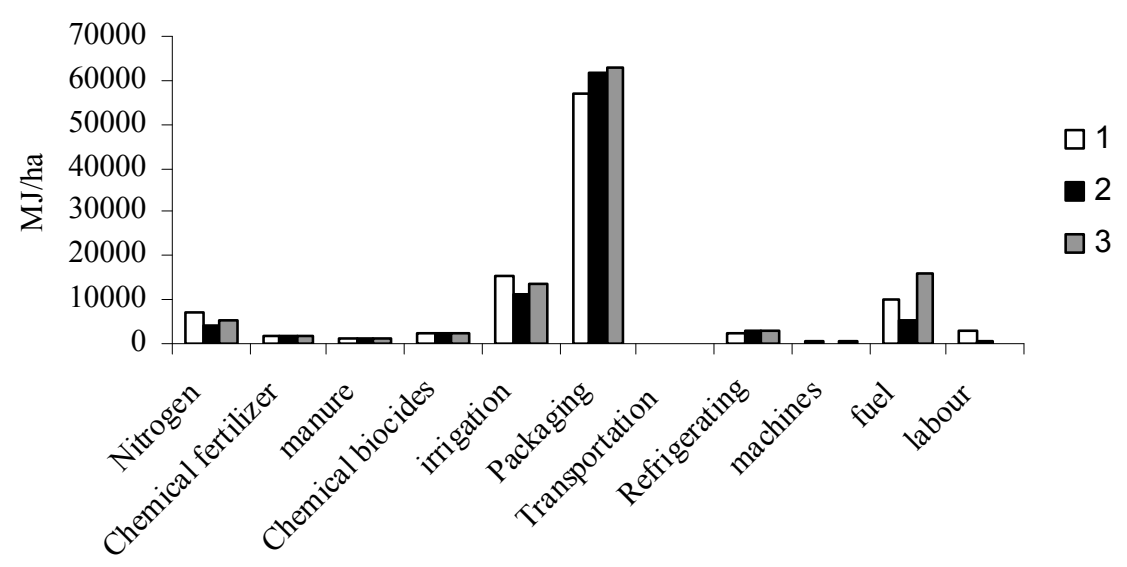

Figure 2. The percentage of the input energies in the mechanization levels 